\title{
Reducing Property Appraisal Bias with Decision Support Systems: An Experimental Investigation in the South African Property Market
}

Evans, K. ${ }^{1}$, Lausberg, C. ${ }^{2}$, and Sui Sang How, $\mathrm{J}^{3}$

1,3 Department of Construction Economics and Management, University of Cape Town, South Africa.

${ }^{2}$ Institute for Real Estate Information Technology, Nurtingen-Geislingen University, Germany.

To cite this article: Evans, K., Lausberg, C. \& Sui Sang How, J. (2019). Reducing Property Appraisal Bias with Decision Support Systems: An Experimental Investigation in the South African Property Market. Journal of African Real Estate Research, 4(1), pp.108-138. DOI: 10.15641/jarer.v4i1.729.

\begin{abstract}
Background - Researchers have observed that valuation accuracy and valuation variation are caused by human adaptive approaches called cognitive shortcuts. Of particular interest for valuation tasks is the susceptibility of decision-makers to the anchoring and adjustment heuristic, a mental shortcut which involves deliberate and conscious adjustment of values. Various studies have shown that valuers are prone to anchoring to asking price, previous estimates, and other reference points.

Aim - The research aim is to determine the efficacy of a decision-support tool in reducing property appraisal bias.

Setting and Methods - A controlled experimental study design was used. The design in which test persons had to appraise a fictitious property is based on a German study that uses a selfwritten valuation software, adapted to South African conditions. The software comprises two versions, a standard software and a decision-support software. Descriptive statistics and nonparametric testing were used to interpret the results.

Findings - Despite the results not being as robust as expected, the study revealed that test subjects were susceptible to the anchoring bias and that using a decision-support tool can help reduce this and so decrease the valuation variations.

Practical implications - This study heightened the need to counter the effect of bias in valuation. Few studies have delved into debiasing methods and even fewer have used technical tools for this task. Other forms of cognitive shortcuts used by valuers should be incorporated into the decision-support tool, and a similar test run for different valuation settings.
\end{abstract}

Keywords: Appraisal Bias; Anchoring and Adjustment Heuristics; Decision Support Systems 


\section{Introduction}

With the advent of new technology and findings derived from computer science and other fields, interest in using computer-aided technology to improve property valuations has become the focus of much attention. Another area of increased interest is behavioural valuation research which has greatly benefitted from advances in psychology and other fields. Yet the area of overlap between using both technology and insights into human behaviour to improve valuations is largely uncharted territory. Here, decision-support systems (DSS) come into play because their purpose is to support human decision-making, including judgements and estimations, which are a core activity of property appraisals (Shim et al., 2002).

Behavioural researchers assert that valuation is a discipline of social science and must be viewed as an art not a science (Diaz \& Hansz, 2007). Given that valuation is a human activity, judgement bias may occur in the form of random and systematic error, which is regarded as having a greater effect on an investor's decision than random bias would have (Yiu et al., 2006).

Valuation bias is an under or over valuation in relation to the target (Crosby, 2000). It occurs when the valuer or the valuation (i.e. the techniques, processes, systems, etc. used by the valuer) show random or systematic errors. Identifying and examining the normative descriptive gap to align with normative standards is termed 'debiasing' (Tidwell \& Gallimore, 2014). Among the three main debiasing techniques Larrick (2004) identified, technological strategies such as using a DSS are perceived to be more effective than the cognitive or motivational strategies.

To mitigate or eliminate the effects of decision-making bias, DSS have been designed to assist human decision-making processes. With an improved informational display, informational search and reduced processing cost, DSS provide a cognitive incentive system that both enhances the decision-making process and reduces systematic bias. Tidwell and Gallimore (2014) and Lausberg and Dust (2017) found that decision-support technology has the potential to reduce the most prominent bias in real estate valuations: the anchoring bias. While the studies revealed the existence of anchor behaviour, they also showed that computer-based systems can be used to improve appraisal judgement, although many issues remain unresolved. Therefore, further research into the efficacy of decision-support tools presents a great opportunity, especially within the South African property valuation context.

The research question addressed in the study is:

\section{To what extent can the decision support systems help reduce or eliminate property appraisal bias?}

A review of the literature indicates that no study has explored the influence of a decision-support tool in real estate valuation in the context of the South African property market. The correlation of anchoring behaviour and valuation in unfamiliar geographical locations is of particular interest (Tidwell \& Gallimore, 2014). The purpose of this study, therefore, is to test 
the efficacy of the decision support systems in mitigating and reducing anchoring bias in the valuation process.

\section{Literature Review}

\subsection{Property valuation and judgement}

\subsubsection{The valuation process}

Amidu (2011) suggests that valuation is inherently a human activity and a judgemental process due to the heterogeneous nature of property and the lack of transaction information in the market. The author recognises that despite the development of a systematic and structured approach to facilitate consideration of implicit and explicit factors, which could affect valuation outcomes, judgement bias is likely to occur throughout the valuation process.

\subsubsection{Accuracy and variation in valuation}

In valuation variation studies, bias occurs when a valuation produced by one valuer differs from those by other valuers based on the same information and time basis. Joslin (2005), through a questionnaire survey and valuer interviews, found that uncertainty during a valuation affects the accuracy of valuation. Uncertainty in valuation arises from the quantity and quality of comparable evidence, the market condition, the characteristics of the subject property, client pressure and a valuer's subjective opinion (Joslin, 2005; Babawale \& Omirin, 2012; Awuah et al., 2016).

Tidwell and Gallimore (2014) and Awuah et al. (2016) contend that the wide dispersion of market value estimates stems from the inherent characteristics of real property such as size, design, infrastructure, etc. The deficit of open market information forces valuers to use anecdotal or unsystematic information to gather market information. In addition to the disparity in market information, behavioural contention within the valuation process may lead to valuation inaccuracy and variance.

\subsubsection{Decision-making, heuristics and behaviour}

Simon and Newell (1971), who pioneered the theory of human problem solving, found that due to limited processing capacity, people use heuristic methods to solve problems. According to the theory, the human informationprocessing system operates sequentially, with most processing activities occurring in the short-term memory. However, due to the limited capacity of short-term memory and the slow storage capacity in the long-term memory, humans adapt to cognitive shortcuts called heuristics. This adaptive approach is used unconsciously as an efficient way for individuals to reduce complex tasks to simpler judgemental operations. For valuations, the heuristic behaviour is of particular importance because human judgement is central to the process.

In the literature, various types of bias arising from heuristic adaption have been identified. Relevant for this research, drawing on findings by Simon and 
Newell (1971), and Tversky and Kahneman (1974) identify three types of heuristics people use regularly when forming judgements: the representativeness, availability, and the anchoring and adjustment heuristics. Later, other researchers (Arnott, 2006; Evans, 1989; Harvard, 2001a) found many more cognitive shortcuts used by decision-makers.

The anchoring and adjustment heuristic is mainly employed in numerical predictions. Rottenstreich and Tversky's (1997) study on judgement of a disjunctive event, Kruger's (1999) research of rating of one's ability to drive and Griffin and Tversky's (1992) study of confidence judgements, suggest that people use an anchor-and-adjust strategy to solve estimation problems. However, in all cases, due to insufficient adjustment, a biased judgement emerges as the final value remains biased in the direction of the original arbitrary anchor value.

The subconscious use of cognitive shortcuts described above may lead to various forms of bias. In the context of property valuation, Yiu et al. (2006), through a desktop study of appraisal bias, identified the anchoring effect, appraisal smoothing and survival biases as common types of appraisal bias. Appraisal smoothing is classified as a random bias and it arises from a tendency of appraisers to smooth their valuations by using historic data or anchoring their values to previous estimates (Figure 1). Survival bias, put forward by various studies (Bretten \& Wyatt, 2001; Hansz, 2004), relates to client influence on valuations. However, while this type of bias is more systematic in nature and can affect the result to greater extent, Kishore (2006) argues that survival bias is to some extent the result of unethical behaviour by valuers, and thus not necessarily due to cognitive shortcuts.

\section{Appraisal Bias}

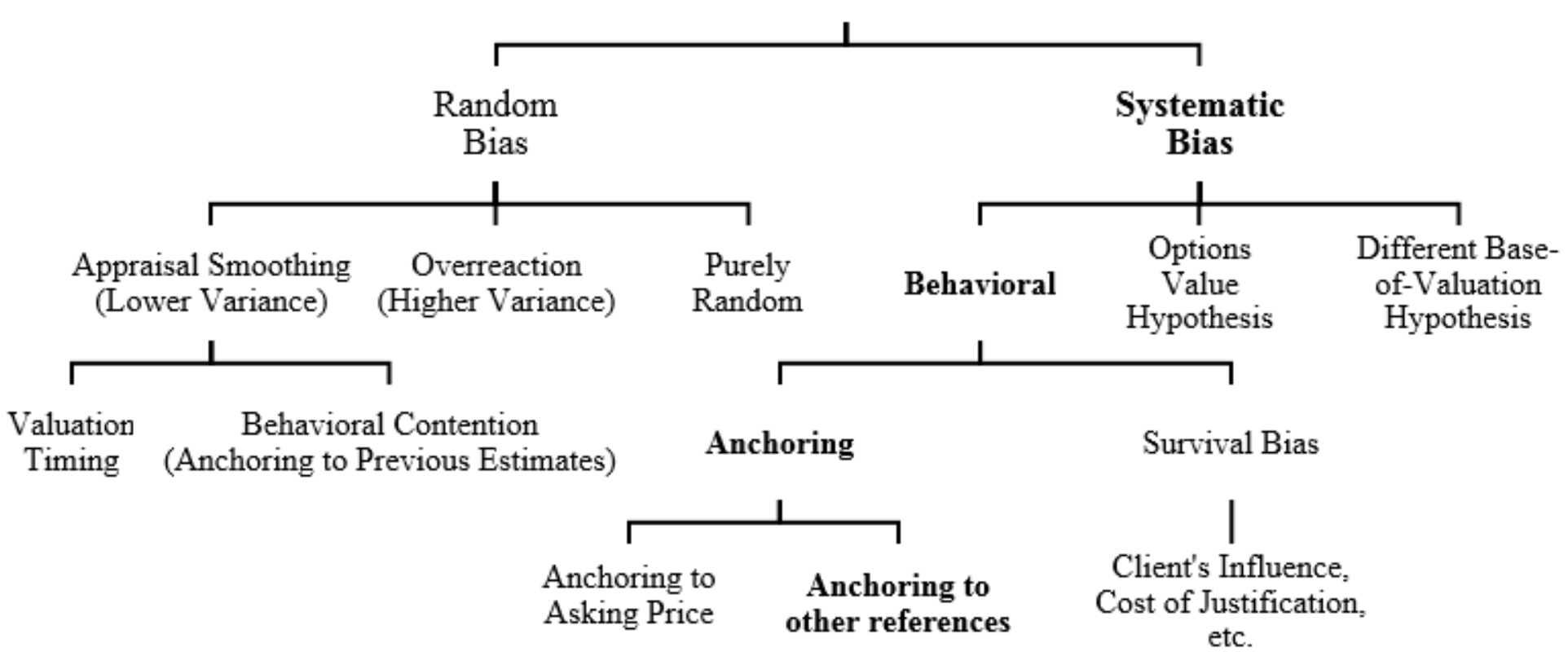

Figure 1: Appraisal bias according to Yiu et al. (2006), as depicted in Lausberg and Dust (2017, p. 334) 


\subsection{Anchoring effects in valuations}

Normatively, valuers should follow valuation procedures before forming a value judgement. The valuer's task is to evaluate property-specific and market information. However, psychological theory supports the notion that valuers are also prone to mental shortcuts when carrying out a task. Anchoring effects have been observed to be prominent in real estate valuations as the market value inevitably has some subjective elements and the high need for information cannot be satisfied with low information availability (Northcraft \& Neale, 1987; Tidwell, 2011).

\subsubsection{Types of anchoring effects}

There are two types of anchoring effects as distinguished by Epley (2004), who highlights that the anchoring effect covers almost every decision relating to the assimilation of an anchor value. The anchor value can be generated either by an external source or by decision-makers themselves. "Externally provided" anchors and "self-generated" anchors respectively lead to accessibility-based anchoring and adjustment-based anchoring. Although the anchors produce effects of similar characteristics, they are observed to be psychologically different.

Epley and Gilovich (2005) assert that "self-generated" anchors are automatically generated values that are known to be wrong but close to a right answer, and for which deliberate and conscious adjustment is required. Unlike "externally provided" anchors that produce suboptimal results due to the inconsistent retrieval of anchor-related information, "self-generated" anchors lead to adjustment-based anchoring. This heuristic behaviour arises due to insufficient adjustment resulting from a lack of attention and a "satisficing" tendency (Epley \& Gilovich, 2006). An empirical study by Epley and Gilovich (2006) supports the argument of Quattrone et al. (1981) that subjects stop adjusting once a plausible result is reached. In addition, the study finds evidence that adjustment is "effortful", and it is suggested that incentives to engage in effortful thought may diminish the adjustment-based anchoring effects.

\subsection{Countering the anchoring effect in property valuations using debiasing techniques}

Various studies show that valuers do not follow the normative models of rational thinking, which explain the process and product that rational thinking should meet (Northcraft \& Neale, 1987; Diaz, 1990; Quan \& Quigley, 1991; Black \& Diaz, 1996; Diaz \& Hansz, 1997; Black, 1997; Diaz \& Wolverton, 1998; Diaz et al., 1999; Havard, 2001a; Hansz \& Diaz, 2001; Clayton et al., 2001). It is observed that due to the limited human processing capacity, valuers have the tendency to deviate from the normative process when forming judgements. However, the normative-descriptive gap, which leads to systematic bias in valuations, has now drawn researchers' attention to find solutions to mitigate and eliminate this gap. 


\subsubsection{Debiasing techniques}

According to Fischhoff (1982), sources of bias are faulty tasks, misunderstanding of tasks, and mismatch between decision-making and tasks. In his debiasing strategy, he suggests that the decision-maker is the main source of biased judgement rather than the task itself. The strategy is based on an escalation design that aims to improve human performance through the following steps:

(1) Warn the decision-maker of possible deviation without giving a description of the type of bias.

(2) Describe the direction (positive or negative influence) and extent of the bias.

(3) Provide feedback and relate back to the warning message.

(4) Provide support with feedback, such as a programme of training and coaching that would help to overcome the bias effect.

Arkes (1991) supports the classification of the various causes of bias into three broad categories, namely psychophysically-based error, associationbased error and strategy-based error. The author argues that adaptive behaviour is characterised by costs and benefits, which reflects a rational benefit-cost calculation in decision-making. Unlike psychophysically-based errors and associated-based judgement errors, which are regarded as associative, fast, automatic and effortless, strategy-based errors are slower, serially driven and require significant cognitive capacity (Stanovich and West, 2000). Kahneman (2003) contends that the first two adaptive behaviours are intuitive, whereas strategy-based errors are based on reasoning, which is consciously monitored and deliberately controlled.

Based on the taxonomy of judgement behaviour by Arkes (1991), Larrick (2004) identifies three main approaches to address bias. Motivational strategies in the form of incentives and accountability help improve decision performance in some cases. The incentive approach encompasses the principle that people possessing the necessary cognitive capital will apply additional effort to improve outcomes. Equally, accountability, based on the principle mechanism of pre-emptive self-criticism, improves decisionmaking through the motivational effects of social benefits.

Another approach is called "consider the opposite". It relies on individuals applying different views that address the ill-structured processes of associated-based error (Chapman \& Johnson, 1999). Mussweiler et al. (2000) support this approach as it directs attention to alternative evidence that may not have been considered, overconfidence and accessibility-based anchoring effects. Larrick (2004), however, argues that an over-reliance on this technique may affect decision-making accuracy or cause decision-makers to believe in such intentionally biased judgement. Yet another form of cognitive strategy is training to facilitate the learning and application of normative rules. Proper training can also help decision-makers understand heuristic behaviour and to develop the necessary skills to eliminate biased decisions. 
Technological strategies in the forms of group decision-making tools, decision models and decision analysis can also improve the decision-making process. It is argued that while using a group decision system, synergies emerge from experts' interaction and error-checking improves the decision outcome. Similarly, using statistical techniques such as a multiple regression analysis or a decision tree is beneficial in assessing large data sets and analysing alternative outcomes where human processing capacity is limited. Of utmost importance is the use of computing technology to automate much of the decision analysis. DSS are arguably much more efficient as the systems reduce the cost of efforts, which hence improves the effort-accuracy trade-off (Edwards \& Fasolo, 2001).

For valuation tasks that are complex in nature, adopting a socially administered practice (motivational techniques) or an individually administered practice (cognitive strategies) is impractical (Larrick, 2004). Apart from that, Epley and Gilovich (2005) argue that self-generated anchors are essential in forming a value judgement and that setting aside with cognitive strategies is counterproductive. While a systematic study of cognitive heuristics can provide normative recommendations, Gigerenzer (2004) contends that it will be difficult to know whether the solutions are feasible. As such, it is suggested that debiasing strategies should be geared towards refining the psychological processes (Epley \& Gilovich, 2005). Technologists regard debiasing strategies in the form of DSS to be better at improving the psychological processes.

\subsubsection{Decision support systems}

With the advance in information technology, computerised systems have developed that attempt to improve the effectiveness of decision-making (Arnott \& Pervan, 2005). The aim of decision support tools is to provide an interactive platform whereby computerised systems provide assistance by automating the structured part of the problem while the individual deals with the complex unstructured elements of the decision (Silver, 1991).

DSS have various attributes that can be tailored to the type of decisionmaking environments they support. Silver (1988) undertook a descriptive analysis and classified the systems into three tiers: functional capabilities, user view of system components, and system attributes. The first two tiers represent the information processing capabilities and the system configuration that comprise DSS. The system attributes represent the collective statements and the component relationships in a DSS, and it is generally characterised by the types of system design. According to Silver (1988), the system can be designed to restrict its users' decision-making processes (system restrictiveness), provide guidance in constructing and executing decision-making processes (system guidance) or provide specialised support for decision-making processes (system focus). These attributes determine the possible effect of the DSS on users' decision-making processes - what users can and will do to the system. 
Hoch and Schkade (1996) observe that DSS research is technology-driven and mainly focuses on how decisions can be improved, while behavioural research focuses on the process of decision-making. The lack of understanding of the psychological effects and the incorporation of contemporary behavioural decision-making research limit the application and usefulness of decision-support tools (Elam et al., 1992). Hoch and Schkade (1996) demonstrate that incorporating cognitive aids into a traditional decision-support tools can effectively improve decisions. The empirical study shows that in a low predictable environment, the traditional DSS, which support human information processing limitations via a database of historical information, produce less reliable outcomes. When combining cognitive model-based support systems with traditional DSS, the forecasting task in uncertain settings has better outcomes. Similarly, Singh (1998) developed a conceptual framework to explore the efficacy of integrating aspects of cognitive aids into the technological tools for improving strategic execution.

\subsubsection{Decision support systems and the cost-benefit framework of cognition}

Theory asserts that decision-making is contingent upon the effort required to make a decision and the accuracy of the outcome (Payne, 1982). The tradeoffs between accuracy and effort in decision-making are largely supported by various empirical, simulation and conceptual studies (Todd \& Benbasat, 1991).

Kleinmuntz and Schkade (1993) argue that information displays affect decision makers' choice processes through an adaptive mechanism of accuracy and effort trade-off. Visual representations are mainly characterised by the form, organisation and sequence of information, and are defined as follows:

Form relates to the way individual items of information are displayed (such as numerical, verbal or pictorial representation).

Organisation refers to the way that individual items of information are shown in meaningful patterns or structures (e.g. table or list).

Sequence denotes the order that individual items or group of items appear (e.g. alphabetical or chronological order).

Schkade and Kleinmuntz (1994) found evidence that organisation has the greatest influence on information acquisition. While form displays primarily influenced information combination and evaluation, organisation was noted as requiring the largest effort requisition by decision-makers. Display sequence had fewer and smaller effects on acquisition processes.

Within the real estate literature, studies suggest that information presentation may influence decision-maker perception. Havard (2001b) examines the effect of information display on bias in commercial valuation and observes that a tabulated display can reduce bias in valuation. Although the extent of its effectiveness is inconclusive, the simple fact that data presentation changes the outcome of the valuation task is highly significant for decision processes. Similarly, Jin and Gallimore (2010) observe that information display, when 
used to manipulate framing effects, can change an individual's decision making processes.

\subsubsection{Use of decision-support tools for real estate valuations}

Property valuation can be done on two levels (individual or portfolio) and in two ways (one-by-one or mass appraisal). In mass valuation, automated valuation models (AVM) have become market standard. They often have built-in procedures and sometimes even artificial intelligence to eliminate bias by shifting decision power from humans to machines. This is not the case in individual appraisals. The majority of valuers either use Microsoft Excel or one of the many valuation software packages on the market. Unlike mass valuation, manual valuation software lacks the computational intelligencebased techniques. Lausberg and Dust (2017) contend that not even leading software packages such as Argus or Cougar, which otherwise provide sophisticated information handling abilities, provide the necessary support for decision-making. Hence, for studying the effect of decision-support on valuations, researchers have to either build their own experimental systems or to use other systems such as market information systems in combination with valuation software.

Using the experimental concept of Northcraft and Neale (1987), George et al. (2000) built a real estate appraisal DSS to examine the systems' efficacy in mitigating and eliminating the anchoring and adjustment bias. Their findings reinforced Northcraft and Neale's (1987) observation that subjects are susceptible to anchoring effects when exposed to an anchor value. Use of a computer-based DSS, however, did not support assumptions that with the assistance of an automated system, the strength of the anchoring and adjustment bias would be reduced. The authors speculate that the reason for anchoring and adjustment remaining robust lies within the design of the computer-based system. An understanding of the rationalisation of the process and better debiasing techniques are required for improvement.

Contrary to the findings of George et al. (2000), recent empirical studies by Tidwell and Gallimore (2014), and Lausberg and Dust (2017) show that a decision-support tool can be effective in debiasing valuation judgement. Tidwell and Gallimore (2014) use an existing proprietary tool, CoStar ${ }^{1}$, to examine the efficacy of decision-support tools in debiasing valuation judgements of industrial vacant land. They use a two-factor randomised experiment comprising a previous expert's opinion and the introduction of a decision-support tool. Unlike the treatment group that had access to the software, the group exhibited evidence of asymmetric and divergent results. The experiment supports the thesis that use of a computer-based system may subdue the anchoring heuristic in the valuation task.

Another interesting finding by Tidwell and Gallimore (2014) is that decision support systems can encourage extensive consideration of available market

\footnotetext{
${ }^{1}$ CoStar is not a DSS in the narrow sense of the word. It is in essence a database of commercial real estate information such as sales comparables that comes with sophisticated analytical tools.
} 
information during the judgement process. A previous study by Diaz et al. (2004) revealed that valuers operating in unfamiliar markets are unlikely to increase comparable sales search. The lack of sales search effort reinforces Simon and Newell's (1971) thesis that people seek cognitive efficiency and reduce cognitive effort when faced with a complex situation. This observation, however, was made without the use of easily accessible external tools. With the decision-support tool, Tidwell and Gallimore (2014) observe and support technologists' view that high informational search costs can potentially be reduced thereby encouraging subjects to use more comparable sales information during the valuation task.

Lausberg and Dust (2017) use a self-written Microsoft Excel decision-support tool to assess the market value of an office building, integrating features of decision support believed to be effective in reducing the anchoring effect. The software consists of three levels of intervention that differ in degree of support, namely:

Standard (STD) version providing no decision support.

Modified (MOD) version introducing a simple warning message with an explanation of the anchoring effect so that test subjects can adjust their value opinion with a sliding switch.

Decision Support System (DSS) version with multiple features intended to produce more reliable outcomes such as optimised information display.

The experiment shows that with a fully supported DSS, the anchoring effect and valuation variation can be reduced. The DSS version produced more accurate market values with fewer dispersed results than the standard and modified versions. Lausberg and Dust (2017) assert that variability is reduced because users are required to follow normative procedures and are forced to spend more time on decision-making. In fact, with the requirement to compare market data sources, readings and data input to make a rational opinion, it is observed that processing time is longer with the DSS version.

On the other hand, the results were less convincing using only the modified version; the frequency distribution graph shows a distribution with outliers. While Lausberg and Dust (2017) presume that the warning message may not have been explicit enough or may have caused confusion, a similar study by George et al. (2000) shows that use of a warning message only is not sufficient to address the anchoring effects.

\section{Methodology}

\subsection{The experimental method}

Experimental research is a systematic approach that studies behaviours (dependent variables), when some factors (independent variables) are manipulated under the control of the experimenter, while other factors are held constant (extraneous variables) (Goodwin, 2009). Breakwell et al. (2012) contend that independent variables must have at least two levels of condition or situations that can be used to compare the intentional manipulation of variables. One group should comprise a treatment variable 
(experimental group) while the other group should have no treatment intervention (control group).

Within the valuation field, most studies on the anchoring and adjustment heuristic used experimental methods to explore the cognitive mechanisms employed by subjects. These included the works of Northcraft and Neale (1987) and Diaz et al. (1999). In the case of George et al. (2000), Tidwell and Gallimore (2014), and Lausberg and Dust (2017), computer systems were used for the experiments. The three studies used different anchors: the asking or listing price (George et al., 2000), the previous value judgement of an anonymous expert (Tidwell \& Gallimore, 2014), and the book value of the property (Lausberg \& Dust, 2017). The anchor was purposely set low as a previous study by Hansz and Diaz (2001) demonstrated a natural tendency to anchor towards higher values.

\subsection{The research instrument}

The experimental design of the research instrument used to collect data for this study, is based on the Lausberg and Dust (2017) design, with some modification to suit the South African property valuation context.

\subsubsection{The subject property}

For the valuation exercise, care was taken to create a case that was fictitious, but as close to reality as possible; not too complex, so it could be valued in less than 30 minutes, but with enough challenging features to make even seasoned valuers think and give them some leeway on their decisions. A Cape Town office property valuer provided information on a typical office building and current market data:

- Type and location of property: Cape Town CBD office building.

- Size and age: five units, 10 years of age with a lettable area of $1,368 \mathrm{sqm}$.

- Different lease outlet: a vacant unit and four units featuring lease terms between one and nine years.

- Tenancy information: law firms with a good credit record.

- Other attributes: aligned with law firms' particular use, e.g. close proximity to the High Court.

- Other information: current expenses and 10 outdoor parking spaces.

The subject property was assumed to have a high rental ability, normal maintenance costs and a long useful life.

To prevent results being distorted due to differences in market knowledge, all participants received a memorandum which was similar to a broker's information memorandum and included the following information:

- General information, location and site description, including briefing by the owner.

- Market information from various sources comprising: 


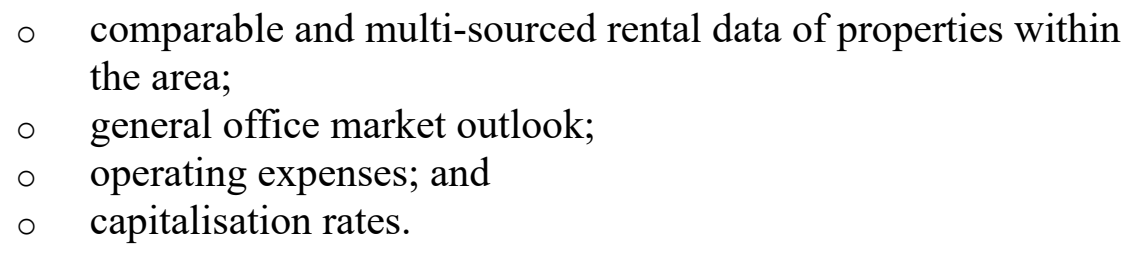

Unlike Lausberg and Dust (2017), who used book value as an anchor value, this study uses the (low) asking price. In the South African property market, book value is not a good proxy for transaction price as it refers to the net worth of a property according to its financial statements. Similarly, assessed values, used to determine the value of a property for tax purposes, are inappropriate to use as an anchor value for the study (Cypher \& Hansz, 2003). Therefore, the memorandum refers to the owner's pending sale price based on an unsanctioned expert valuation opinion of R11 million.

\subsubsection{The software}

The valuation system is an adaptation of Lausberg and Dust's (2017) experimental Microsoft Excel software, but with information relevant to the South African property market and some improvements.

As was observed under the previous study, the modified version did not produce conclusive results; therefore, this study only used the standard (STD) and DSS software versions.

When the Microsoft Excel version is activated, the first page contains general information and instructions to start the experiment (Appendix A). The second page provides an interface for calculating market value (Appendices $\mathrm{C}$ and D) and the last page collects statistical data (Appendix B). Figure 2 shows the calculation core for both the STD and DSS versions. The steps where estimations, judgements or other types of decisions have to be made are marked with an arrow, i.e., where decision-support is applicable. Obviously, this is the case for all steps except for the most basic mathematical calculations. 


\section{Income Approach}

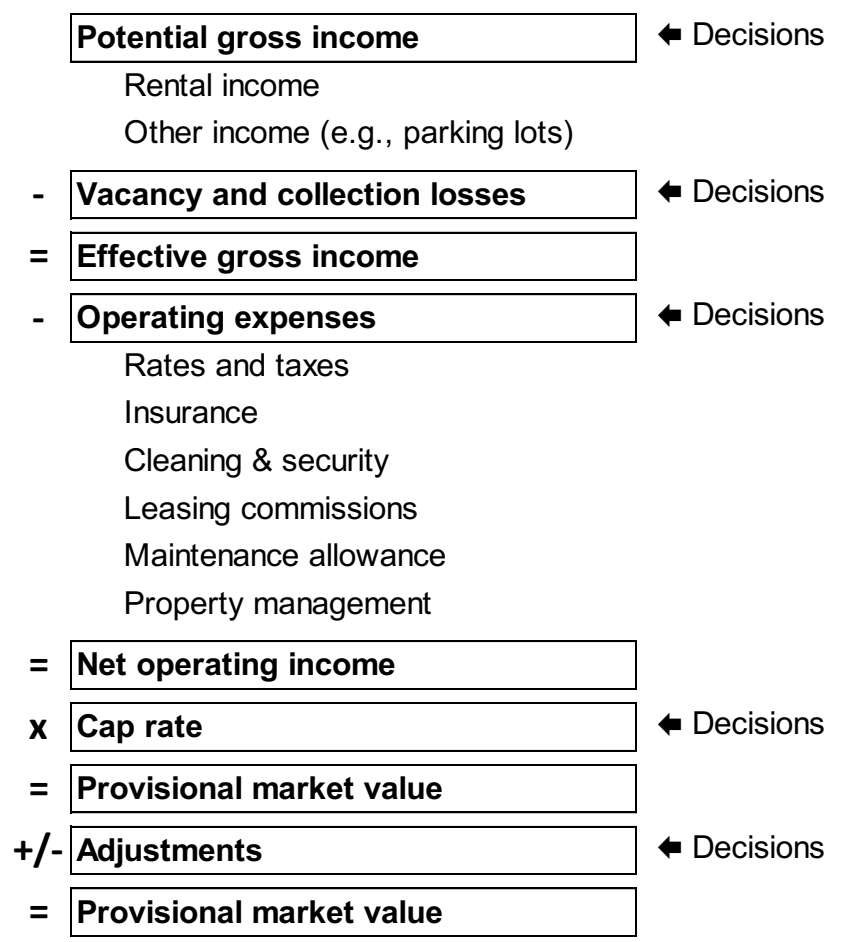

Figure 2: Calculation core for the STD and DSS versions

The standard version (see Appendices A, B and C) provides a basic setup with mandatory fields for calculating market value. The participant enters figures from the documents into the software once data has been interpreted and analysed. In this version, the programme does not support decisions arising at various levels of the decision-making process.

The decision-support tool provides various features of DSS within the basic spread sheet (see Appendices A, B and D). To avoid deviation from the normative approach, the DSS version provides a process-orientated procedure, highlighting each step to be undertaken to complete the valuation tasks. Various graphical displays, emoticons, comparable tables, explanations and data analysis features provide subjects with necessary support to evaluate the quality of market data. Warning messages and plausibility checks are incorporated into the software for attentional and correctional measures for data input that seems inappropriate. In addition to the various decision support features, the DSS version includes a final "sanity check" feature that explains the anchoring effects and allows subjects to adjust their estimate using a slider.

\subsection{Hypotheses}

The hypotheses to answer the research question of the extent to which decision-support systems help to reduce property appraisal bias are:

$\mathrm{H}_{1}$ : The valuation variation is lower if the valuer is de-biased and supported in his decisions. 
$\mathrm{H}_{2}$ : The anchoring effect is reduced if the valuer is de-biased and supported in his decisions.

The anchoring effect was not measured. It was, however, considered an indicator that the anchoring effect was present when a participant made an adjustment to the value once the alerting function in the DSS version of the experiment was displayed.

\subsection{The empirical procedure}

A random sampling method was used to distribute one of the two versions of the valuation tool to the treatment and control groups. The random selection method ensures that no systematic errors occur in the data collection as every member has equal probability of being selected. Both the STD and DSS versions were issued equally.

To increase response rates, participants of the study could win an iPad or one of three iPods via a random draw. In addition to the prize, an hour of continuing education and training, approved by the South African Council for the Property Valuers Profession (SACPVP), was granted to all expert participants.

Data was either received via email or through an online tool. The raw data was debugged and updated into a master Excel file. Then, a plausibility check was carried out to identify and eliminate implausible data sets such as double entries or data with obvious input errors.

\section{Analysis of Data and Discussion}

\subsection{Data collection}

The sample consists of both expert valuers and novices. Professional valuers from the SACPVP formed the expert group. The novice group, for whom formal ethical clearance was obtained, consisted of final-year undergraduate and postgraduate students in construction studies, property studies and quantity surveying degrees at the University of Cape Town (UCT).

Most participants were contacted via email using the UCT student information system or through the South African Institute of Valuers (SAIV). The Professional and Projects Register 2010 and direct telephonic contacts were also used to identify additional contacts, to whom information was sent. The information pack consisted of a covering letter, an instruction document, a Microsoft Excel file and a memorandum containing information about the subject property and the market. Direct assistance was provided during the experimental period.

The study took place over a period of 3 months for experts and 4 months for the novices. A total of 1,345 property valuers and 183 students were officially invited to the study. Ninety-three data sets were received of which 44 were from experts (3.20\% response rate) and 49 were from novices $(26.78 \%)$. The 
response rates are in line with expectations for online surveys among these groups of respondents.

Table 1 shows that 42 experts and 46 novices were considered valid data sets. The distribution within sub-groups was fairly balanced with $52.27 \%$ being students and $47.73 \%$ being experts. The study of Lausberg and Dust (2017), on which this study is based, had a similar sample size of 43 experts and 46 novices but with a higher response rate from a lower total number of participants contacted.

Table 1 : Number of valid participants

\begin{tabular}{|l|l|l|l|}
\hline & Standard & DSS & Total \\
\hline Students & 26 & 20 & 46 \\
\hline Experts & 21 & 21 & 42 \\
\hline Total & $\mathbf{4 7}$ & $\mathbf{4 1}$ & $\mathbf{8 8}$ \\
\hline
\end{tabular}

\subsection{Analysis of the data}

The quantitative data was analysed using Microsoft Excel, the statistical software package SPSS Version 23, and R Studio. Three simple variation measures were used to assess the effectiveness of the decision support tools: range, standard deviation and variation coefficient.

To test the equality of variances, normality for the data sets is tested first. The Jarque-Bera test (jbtest) was used to measure the skewness (S) and kurtosis $(\mathrm{K})$ of the sample for goodness-of-fit of a normal distribution (Bai \& NG, 2015).

The Levene test of homogeneity of variance is performed for normally distributed data. For non-Gaussian distribution, the skewness and kurtosis are examined to determine the appropriate inferential procedure to employ. Either the modified robust Levene-type test or the modified robust BrownForsythe Levene-type test from the median with modified correction-method zero can be applied.

However, for unequal and small sample sizes, the modified robust BrownForsythe Levene-type test is preferred. This test is the Brown-Forsythe test adjusted using Noguchi and Gel's (2010) method, which uses a combined correctional factor with modified Hines-Hines structural zero removal method that applies a scaling factor of two.

For the assumption of homogeneity of variance not to be violated, a significance level of greater than 0.05 must be achieved (H0: VarSTD = VarDSS, $p$-value $\geq 0.05$ ). However, the study aimed to demonstrate that the decision-support tool is more beneficial than standard tools. Hence, at the 5\% significance level, the null hypothesis should be rejected, and statistically significant differences in variances between the observed groups can be concluded.

\subsubsection{Testing of the first hypothesis}


The first hypothesis states that the valuation variation is lower if the valuer is debiased and supported in his decisions.

$$
\text { H0: Variation MVSTD } \geq \text { Variation MVDSS }
$$

Testing the overall sample group

Using three variation measures, the null hypothesis should be rejected if the majority of the measures show a higher variation for DSS than for STD. Table 2 demonstrates the variation measures under the two different software versions. The market values under the STD version range from R9.82 million to R21.57 million $(=120 \%)$ and are higher than the DSS version, which ranges from R9.41 million to R18.9 million (=101\%). Similarly, the standard deviation is slightly higher for the STD version $(=2.16)$ than for the DSS version $(=1.98)$ and is confirmed by the variation coefficient.

Table 2: Variation measures

\begin{tabular}{|l|c|c|}
\hline & STD & DSS \\
\hline $\mathbf{n}$ & 47 & 41 \\
\hline Mean & 13.91 & 13.37 \\
\hline Range (min/max/\%) & $9.82 / 21.57 / 120 \%$ & $9.41 / 18.9 / 101 \%$ \\
\hline Standard deviation & 2.16 & 1.98 \\
\hline Variation coefficient & $15.6 \%$ & $14.8 \%$ \\
\hline
\end{tabular}

To test the significance level of the results, the jbtest was used to examine the normality of the data. The observed asymptotic $\mathrm{p}$-value for the overall sample is summarised in Table 3. Interestingly, the DSS version was normally distributed, while the STD data and the overall sample were far from a Gaussian distribution.

Table 3: Normality test

\begin{tabular}{|l|c|c|c|}
\hline Subsets & JB-Test p-value & Kurtosis & Skewness \\
\hline Overall Sample & 0.002 & 1.577 & 0.621 \\
\hline STD versions & 0.003 & 2.203 & 0.795 \\
\hline DSS versions & 0.632 & 0.566 & 0.333 \\
\hline
\end{tabular}

Using the Microsoft Excel formula to calculate excess kurtosis and skewness, it was observed that all three subsets were fat-tailed and skewed to the right (Table 3). Given the unbalanced and small sample sizes of the data, the modified robust Brown-Forsythe Levene-type test from the median with modified correction-method zero was applied (Table 4). At the 0.05 level of significance, the null hypothesis cannot be rejected $(p$-value $=0.885)$ and no statistically significant difference of variance between the two groups can be concluded.

Table 4: Modified Robust Brown-Forsythe Levene-type test

\begin{tabular}{|l|l|l|}
\hline Hypothesis & Test- Statistic & p-value \\
\hline $\mathrm{H}_{1}: \mathrm{Var}_{\mathrm{s} \mathrm{D}}=\mathrm{Var}_{\mathrm{ss}}$ & 0.0212 & 0.885 \\
\hline
\end{tabular}




\section{Testing the sub-sample groups}

The same variation measures and test for significance level were used to test the effectiveness of the DSS version within the expert and student subsamples. As shown in Table 5, the variation measures for both groups were higher under the STD version than under the DSS version.

For the expert group, the market values ranged from R12.09 million to R21.57 million $(=78 \%)$ with the STD version and from R11.5 million to R18.9 million $(=64 \%)$ under the DSS version. The variation coefficient indicates that the spread under the STD version was higher than for the DSS version.

The market values for students were slightly lower than those in the expert group. The values ranged between R9.82 million and R16.83 million $(=71 \%)$ and R9.41 million and R15.12 million $(=61 \%)$ for the STD and DSS versions respectively. The variation coefficient was also greater under the STD version, indicating a higher spread of outcomes than for the DSS version.

Table 5: Variation measures for sub-sample

\begin{tabular}{|l|c|c|c|c|}
\hline \multirow{2}{*}{} & \multicolumn{2}{|c|}{ Experts } & \multicolumn{2}{c|}{ Students } \\
\cline { 2 - 5 } & STD & DSS & STD & DSS \\
\hline Mean & 21 & 21 & 26 & 20 \\
\hline $\begin{array}{l}\text { Range } \\
\text { (min/max/\%) }\end{array}$ & $\begin{array}{c}14.52 \\
/ 78 \%\end{array}$ & 14.30 & 13.41 & 12.40 \\
\hline $\begin{array}{l}\text { Standard } \\
\text { deviation }\end{array}$ & 2.17 & $\begin{array}{c}11.5 / 18.9 / 64 \\
\%\end{array}$ & $\begin{array}{c}9.82 / 16.83 / 71 \\
\%\end{array}$ & $\begin{array}{c}9.41 / 15.12 / 61 \\
\%\end{array}$ \\
\hline $\begin{array}{l}\text { Variation } \\
\text { coefficient }\end{array}$ & $14.97 \%$ & $12.94 \%$ & 2.06 & 1.65 \\
\hline
\end{tabular}

The box plots (Figures 3 and 4) illustrate a similar result. The DSS version produced fewer valuation variation values, and outliers in the expert group were less frequently extreme than with the standard versions. 


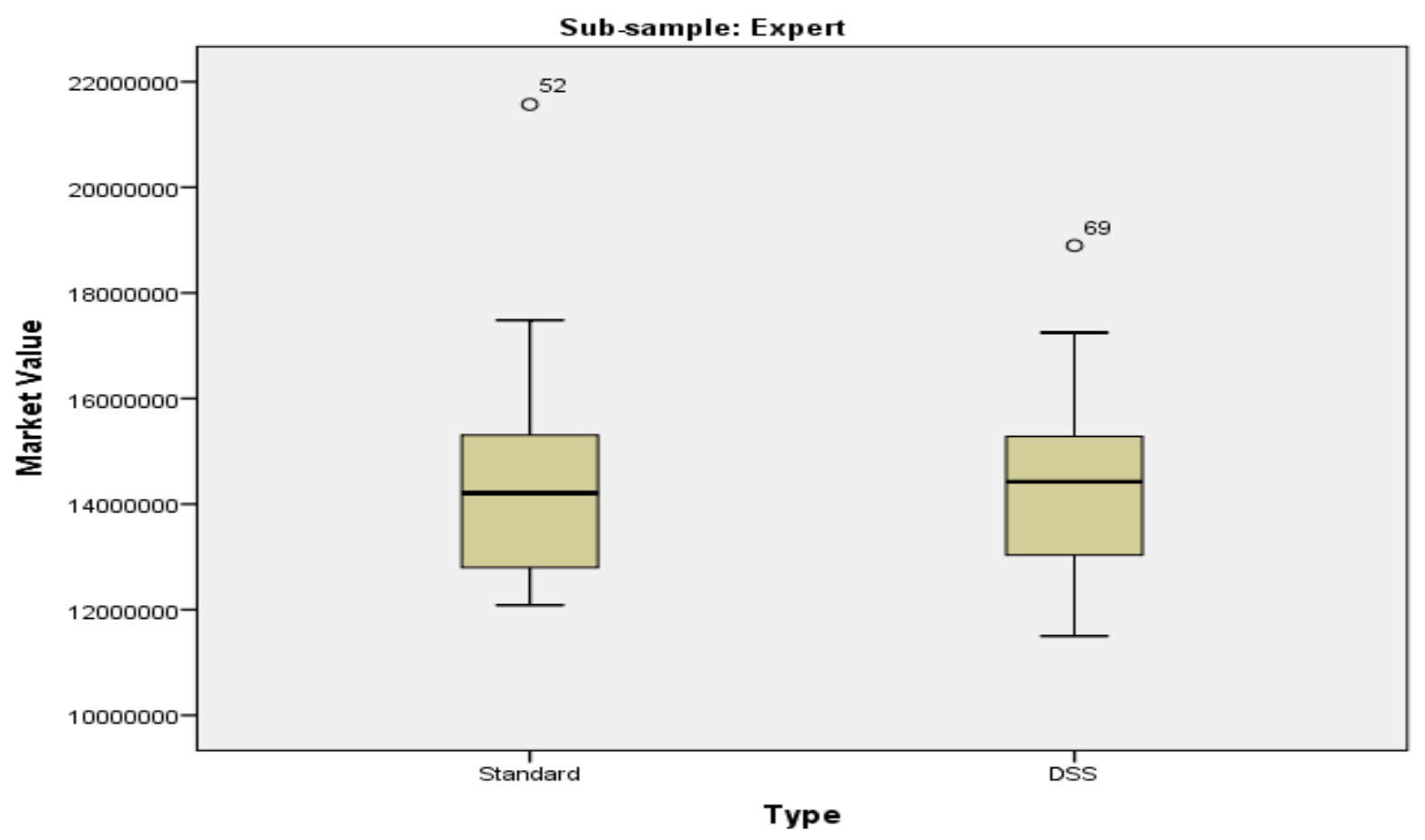

Figure 3: Boxplots comparing DSS vs STD for EXPERT sub-samples

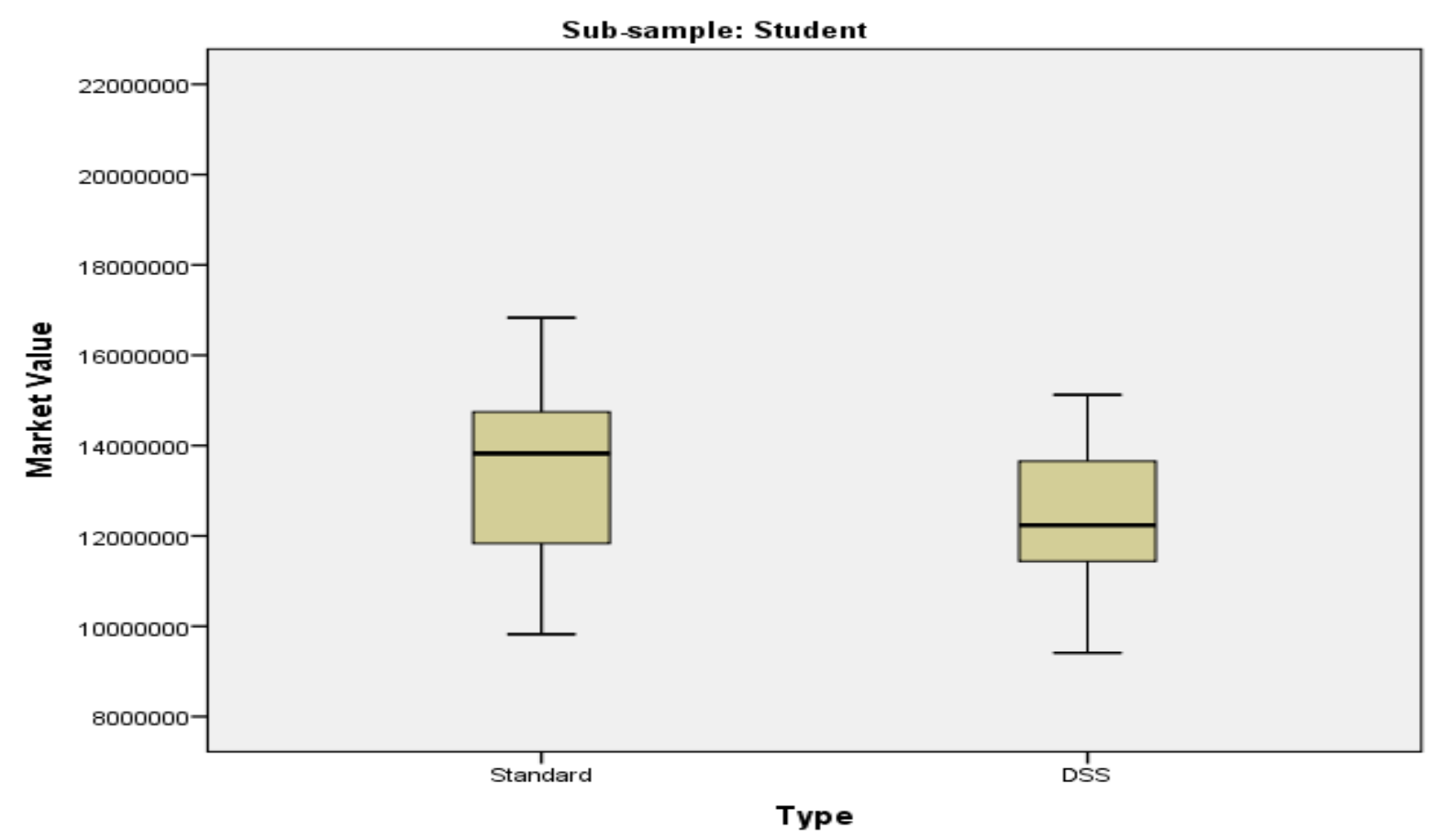

Figure 4: Boxplots comparing DSS vs STD for STUDENT sub-samples

The modified robust Brown-Forsythe Levene-type test from the median with modified correction-method zero, as shown in Table 6, produced similar statistical results to the overall groups. At the 0.05 level of significance, the null hypothesis cannot be rejected, which means that there is no statistically significant difference between the two variance groups. 
Table 6: Modified Robust Brown-Forsythe Levene-type test for subsample

\begin{tabular}{|l|l|l|}
\hline Group & Test- Statistic & p-value \\
\hline Experts & 0.102 & 0.751 \\
\hline Students & 0.964 & 0.332 \\
\hline
\end{tabular}

\subsubsection{Testing of the second hypothesis}

The second hypothesis states that the anchoring effect is reduced if the valuer is debiased and supported in his decision.

\section{H0: Mean Unadjusted MVSTD $\geq$ Mean Adjusted MVDSS}

Table 7 shows the effect of the decision support tool on market values after a warning notice was issued to participants. In the 41 DSS version, 3 experts $(7 \%)$ and 13 novices $(n=32)$ adjusted the market value. This represents a 39\% $(n=16)$ adjustment when test subjects are supported in their decision. Further observations show that in nine cases $(=56 \%)$, the values were negatively adjusted towards the anchor value. Similar to Lausberg and Dust's (2017) observation, the illogical adjustment could be because the warning message was not clear enough and it may have confused the participants.

After adjusting the outcomes for valuation with positive or no adjustment, it was observed that only seven participants $(=22 \%)$ adjusted the market value positively. The mean adjusted market value was $1.37 \%$ higher than the mean unadjusted market value. The results were slightly higher than in Lausberg and Dust's (2017). In a similar vein, it can be concluded that some members of the test groups were susceptible to the anchoring and adjustment effect.

Table 7: Adjustment of market values with the DSS version

\begin{tabular}{|l|l|c|c|c|c|}
\hline \multicolumn{2}{|c|}{} & \multicolumn{2}{|c|}{$\begin{array}{c}\text { Mean market value } \\
(\mathbf{R})\end{array}$} & \multicolumn{2}{c|}{ Adjustment } \\
\cline { 3 - 6 } & unadjusted & adjusted & $\begin{array}{c}\text { Magnitude (\% } \\
\text { of the MV) }\end{array}$ & $\begin{array}{c}\text { Number and \% } \\
\text { of all valuation }\end{array}$ \\
\hline \multirow{2}{*}{ All valuations } & & & $-0.37 \%$ & $3(7 \%)$ \\
\hline & Experts & 14350106 & 14297111 & $0.40 \%$ & $12(32 \%)$ \\
\cline { 2 - 6 } & Students & 12448464 & 12398557 & $-0.38 \%$ & $16(39 \%)$ \\
\hline $\begin{array}{l}\text { Only valuations } \\
\text { with positive or no } \\
\text { adjustment }\end{array}$ & DSS & 13422476 & 13370987 & $0.16 \%$ & $1(3 \%)$ \\
\cline { 2 - 6 } & Students & 14082557 & 14104662 & $3.40 \%$ & $6(19 \%)$ \\
\cline { 2 - 4 } & DSS & 13351241 & 12351241 & $1.37 \%$ & $7(22 \%)$ \\
\hline
\end{tabular}

\section{Conclusions}

The findings of the controlled experiment did not provide robust results regarding the effectiveness of the decision-support tool in relation to removing or eliminating property appraisal bias. However, the study revealed some evidence that the computerised tool can help counteract the cognitive mechanism generated during valuation tasks. In particular, the warning feature, which helps identify the psychological processes of the anchoring effect, was more beneficial for novices. 
When comparing the tools, descriptive statistics showed that the spread was more frequent in the STD version than in the DSS version. Similar observations were made for individual groups and for experts both with and without market knowledge.

Statistical tests showed no significance at the 0.5 level that the valuation variations would be reduced with the given DSS tool. A similar observation, at the 0.05 level of significance, was made under Lausberg and Dust's (2017) experimental research. However, unlike the German study that demonstrated some evidence of the benefits of the DSS tool at the $1 \%$ level of significance, this study could not support similar results. This can be explained by the fact that, unlike the previous study, which shows German valuers were unaware of making decisions during valuation tasks (Lausberg and Dust, 2017), in the present situation, South African test subjects were possibly more conscious when providing value judgements.

Basic descriptive statistical measurements show some evidence that the decision-support tools can help debias decisions. Although the significance test did not fully support the efficacy of the DSS tool, it is observed that at various decision levels of the valuation process, a decision support system can produce better outcomes than the standard tool. There was also evidence of the anchoring and adjustment heuristic, and it was observed that the computerised system can help counteract the unwanted cognitive mechanism generated by inexperienced decision-makers.

\section{Implications for Valuation Practice and Research}

The use of technological strategies to improve the psychological processes associated with valuation tasks is still at an early stage. The experimental tool Lausberg and Dust (2017) developed has demonstrated that a specific software can to some degree improve the valuation quality. That is an important goal, but obviously the software needs to be enhanced and other measures have to be taken before the tool can be useful in practice. In our opinion, there are five areas that researchers, software developers, educators and practitioners have to work on:

Firstly, the current software only incorporates anchor values from an external source. Behavioural studies undertaken by Diaz and Wolverton (1998) and others, however, have shown that experts rely heavily on their personal experience when forming a value judgement. The internally derived value opinion is a strong determinant of the final value decision. Thus, by incorporating the valuer's initial value opinion, the cognitive features of the DSS software could "weight" the final value outcome for possible anchoring effects.

Secondly, the warning messages need to be more explicit, and statistical analysis of market data and risk valuation, as identified by Lausberg and Dust (2017), should be incorporated into the decision-support tool. Moreover 
insights from ergonomics and computer science should be used to increase the usability and, thus, the effectiveness of the software.

Thirdly, the experiment needs to be replicated with experts on various levels of experience and expertise, for other types of properties and using different valuation methods. Other forms of heuristics, such as the representativeness and availability heuristics, should be included in the experiment to establish their impact on valuation outcomes. Furthermore, the experiment should be expanded to other debiasing methods, especially changes in process and training. In our view this type of software can be a useful supplement to existing procedures, it is not meant to replace the valuer.

Fourthly, the developers of valuation software should engage in the further development of their products in the direction of decision support. So far, most programmes are better calculators that do not support the appraiser in his decisions. However, we believe that decision support is both a key to improving the valuation quality and a means for traditional valuation tools to differentiate themselves from the automated valuation models, which are superior to them in efficiency, but often lack effectiveness.

Finally, the foundation of valuation decision-making processes must be reinforced. Behavioural contentions that have been addressed in the real estate property literature for many years must finally be discussed and presented both to students and to experts at large. Amidu (2011) highlights the needs for property valuation education, improvement in professional standards, a code of conduct, and accountability to help counteract and possibly overcome dysfunctional behaviour in value judgement tasks.

\section{Acknowledgments}

\subsection{Source for this research paper}

This paper is based on work undertaken by Mr Jesse Sui Sang How, submitted in partial fulfilment of the requirements of the degree of MSc in Property Studies at the University of Cape Town, South Africa.

\subsection{Source of support}

The authors received financial support from the Institute for Real Estate Information Technology (IMMIT) at Nürtingen-Geislingen University, sponsored by Aareon AG.

\section{References}

Amidu, A.R. (2011). Research in Valuation Decision Making Processes: Educational Insights and Perspectives. Journal of Real Estate Practice and Education, 14(1), pp.19-33. 
Arkes, H. (1991). Costs and Benefits of Judgement Errors: Implications for Debiasing. Psychological Bulletin, 110(3), pp.486-498.

Arnott, D. \& Pervan, G. (2005). A critical analysis of decision support systems research. Journal of Information Technology, 20, pp.67-87.

Arnott, D. (2006). Cognitive biases and decision support systems development: a design science approach. Information Systems Journal, 16, pp.55-78

Awuah, K.G.B., Proverbs, D., Lamond, J. \& Gyamfi-Yeboah, F. (2016). An evaluation of property valuation practice in Sub-Saharan Africa: A Case Study of Ghana. Project Report. London: RICS.

Babawale, G.K. \& Omirin, M. (2012). An Assessment of the relative impact of factors influencing inaccuracy in valuation. International Journal of Housing Markets and Analysis, 5(2), pp.145-160.

Bai, J. \& NG, S. (2005). Tests for skewness, kurtosis, and normality for time series data. Journal of Business \& Economic Statistics, 23(1), pp.4980.

Black, R.T. (1997). Expert property negotiators and pricing information, revisited. Journal of Property Valuation and Investment, 15(3), pp.274-281.

Black, R.T. \& Diaz, J.III (1996). The use of information versus asking price in the real property negotiation process. Journal of Property Research, 13(4), pp.287-297.

Breakwell, G., Smith, J. \& Wright, D. (2012). Research methods in psychology. London: Sage.

Bretten, J. \& Wyatt, P. (2001). Variance in commercial property valuations for lending purposes: an empirical study. Journal of Property Investment \& Finance, 19(3), pp.267-282.

Chapman, G. \& Johnson, E. (1999). Anchoring, Activation, and the Construction of Value. Organizational Behaviour and Human Decision Processes, 79(2), pp.115-153.

Clayton, J., Geltner, D. \& Hamilton, W. (2001). Smoothing in commercial property valuations: Evidence from individual appraisals. Real Estate Economics, 29(3), pp.337-360.

Crosby, N. (2000). Valuation accuracy, variation and bias in the context of standards and expectations. Journal of Property Investment \& Finance, 18(2), pp.130-161.

Cypher, M. \& Hansz, J. (2003). Does assessed value influence market value judgements? Journal of Property Research, 20(4), pp.305-318.

Diaz, J. III (1990). How appraisers do their work: a test of the appraisal process and the development of a descriptive model. The Journal of Real Estate Research, 5(1), pp.1-15.

Diaz, J. III (2002). Behavioural research in appraisal and some perspectives on implications for practice. RICS Foundation Research Review Series. London: RICS Foundation.

Diaz, J. III. \& Hansz, A. (1997). How valuers use the value opinions of others. journal of Property Valuation \& Investment, 15(3), pp.256-260.

Diaz, J. III. \& Hansz, A. (2007). Understanding the behavioural paradigm in property research. Pacific Rim Property Research Journal, 13(1), pp.6-34. 
Diaz, J. III. \& Wolverton, M. (1998). A Longitudinal Examination of the Appraisal Smoothing Hypothesis. Real Estate Economics, 26(2), pp.349-358

Diaz, J. III, Gallimore, P. \& Levy, D. (2004). Multicultural examination of valuation behaviour. Journal of Property Investment \& Finance, 22(4), pp.339-346.

Diaz, J. III, Zhao, R. \& Black, R. (1999). Does contingent reward reduce negotiation anchoring? Journal of Property Investment \& Finance, 17(4), pp.374-379.

Edwards, W. \& Fasolo, B. (2001). Decision Technology. Annual Review of Psychology, 52(1), pp.581-606.

Elam, J., Jarvenpaa, S. \& Schkade, D. (1992). Behavioural Decision Theory and DSS: New Opportunities for Collaborative Research. In: E. Stohr \& B. Konsynski, (eds). Information Systems and Decision Processes. Los Alamitos, CA: IEEE Computer Science Press. pp. 51-74.

Epley, N. (2004). A Tale of Turned Decks? Anchoring as Accessibility and Anchoring as Adjustment. In: D. Koehler \& N. Harvey, (eds). Blackwell Handbook of Judgement \& Decision Making. Malden, MA, Blackwell, pp.240-257.

Epley, N. \& Gilovich, T. (2005). When effortful thinking influences judgemental anchoring: Differential effects of Forewarning and Incentives on self-generated and externally provided anchors. Journal of Behavioural Decision Making, 18(3), pp.199-212.

Epley, N. \& Gilovich, T. (2006). The anchoring-and-adjustment heuristic: Why the adjustments are insufficient. Association for Psychological Services, 17(4), pp.311-318.

Evans, J.S.B. (1989). Bias in human reasoning: Causes and consequences. Hove: Erlbaum.

Fischhoff, B. (1982). Debiasing. In: D. Kahneman, P. Slovic \& A. Tversky, (eds). Judgement under uncertainty: Heuristics and biases. Cambridge: Cambridge University Press. pp.422-444.

George, J.F., Duffy, K. \& Ahuja, M. (2000). Countering the anchoring and adjustment bias with decision support systems. Decision Support Systems, 29(2), pp.195-206.

Gigerenzer, G. (2004). Fast \& Frugal Heuristics: The Tools of Bounded Rationality. In: D. Koehler \& N. Harvey, eds., Blackwell Handbook of Judgement \& Decision Making. Malden, MA: Blackwell. pp.62-88.

Goodwin, C.J. (2009). Research in psychology: Methods and design. $6^{\text {th }}$ edition. New York: John Wiley \& Sons.

Griffin, D. \& Tversky, A. (1992). The weighing of evidence and the determinants of Confidence. Cognitive Psychology, 24(3), pp.411435.

Hansz, J.A. (2004). The use of a pending mortgage reference point in valuation judgement. Journal of Property Investment \& Finance, 22(3), pp.259-268.

Hansz, J.A. \& Diaz, J.III. (2001). Valuation Bias in Commercial Appraisal: A Transaction Price Feedback Experiment. Real Estate Economics, 29(4), pp.553-565.

Havard, T.M (2001a). Valuation reliability and valuer behaviour. RICS Foundation Research Paper Series 4(1). London: RICS Foundation. 
Havard, T.M (2001b). An experimental evaluation of the effect of data presentation on heuristic bias in commercial valuation. Journal of Property Research, 18(1), pp.51-67.

Hoch, S. \& Schkade, D. (1996). A Psychological Approach to Decision Support Systems. Management Science, 42(1), pp.54-64.

Jin, C. \& Gallimore, P. (2010). The effects of information presentation on real estate market perceptions. Journal of Property Research, 27(3), pp.239-246.

Joslin, A. (2005). An investigation into the expression of uncertainty in property valuations. Journal of Property investment \& Finance, 23(3), pp.269-285.

Kahneman, D. (2003). A perspective on judgement and choice: Mapping bounded rationality. American Psychologist, 58(9), pp.697-720.

Kishore, R. (2006). Theory of Behavioural Finance and its Application of Property Market: A Change in Paradigm. Paper presented at the $12^{\text {th }}$ Pacific Rim Real Estate Society Conference, Auckland, New Zealand, January 22-25.

Kleinmuntz, N. \& Schkade, D. (1993). Displays and Decision Processes. Psychological Science, 4(4), pp.221-227.

Kruger, J. (1999). Lake Wobegon be gone! The "below-average effect" and the egocentric nature of comparative ability judgements. A Journal of Personality and Social Psychology, 77(2), pp.221-232.

Larrick, R.P. (2004). Debiasing. In: D. Koehler \& N. Harvey, (eds). Blackwell Handbook of Judgement \& Decision Making. Malden, MA: Blackwell. pp.316-337.

Lausberg, C. \& Dust, A. (2017). Reducing the Appraisal Bias in Manual Valuations with Decision Support Systems. In: M. D'Amato \& T. Kauko, (eds). Advances in Automated Valuation Modelling. Springer: Berlin/Heidelberg. pp.331-343.

Mussweiler, T., Strack, F. \& Pfeiffer, T. (2000). Overcoming the inevitable anchoring effect: considering the opposite compensates for selective accessibility. The Society for Personality and Social Psychology, 26(9), pp.1142-1150.

Noguchi, K. \& Gel, Y.R. (2010). Combination of Levene-type tests and a finite-intersection method for testing equality of variances against ordered alternatives. Journal of Nonparametric Statistics, 22(7), pp.897-913.

Northcraft, G.B. \& Neale, M.A. (1987). Experts, amateurs and real estate: an anchoring-and-adjustment perspective on property pricing decisions. Organizational Behaviour and Human Decision Processes, 39(1), pp.84-97.

Payne, J. (1982). Contingent Decision Behaviour. Psychological Bulletin, 92(2), pp.382-402.

Quan, D.C. \& Quigley, J.M. (1991). Price formation and the appraisal function in real estate markets. The Journal of Real Estate Finance and Economics, 4(2), pp.127-146.

Quattrone, G.A., Lawrence, C.P., Finkel, S.E. \& Andrus, D.C. (1981). Explorations in anchoring: The effects of prior range, anchor extremity and suggestive hints. Unpublished manuscript, Stanford, CA: Stanford University. 
Rottenstreich, Y. \& Tversky, A. (1997). Unpacking, repacking and anchoring: Advances in support theory. Psychological Review, 104(2), pp.406-415.

Schkade, D.A. \& Kleinmuntz, D.N., (1994). Information displays and choice processes: Differential effects of organization, form, and sequence. Organizational Behaviour and Human Decision Processes, 57(3), pp.319-337.

Shim, J.P., Warkentin, M., Courtney, J.F., Power, D.J., Sharda, R. \& Calsson, C. (2002). Past, present and future of decision support technology. Decision Support Systems, 33(2), pp.111-126.

Silver, M. (1988). Descriptive Analysis for Computer-Based Decision Support. Operational Research, 36(6), pp.904-916.

Silver, M. (1991). Decisional Guidance for Computer-Based Decision Support. MIS Quarterly, 15(1), pp.105-122.

Simon, H.A. \& Newell, A. (1971). Human problem solving: The state of the theory in 1970. American Psychologist, 26(2), pp.145-159.

Singh, D. (1998). Incorporating cognitive aids into decision support systems: the case of the strategy execution process. Decision Support Systems, 24(2), pp.145-163.

Stanovich, K. \& West, R. (2000). Individual differences in reasoning: Implications for the rationality debate? Behavioural and Brain Sciences, 23(5), pp.645-726.

Tidwell, O.A. (2011). An investigation into appraisal bias: the role of decision support tools in debiasing valuation judgements. Ph.D. Thesis. Georgia State University.

Tidwell, O.A. \& Gallimore, P. (2014). The influence of a decision support tool on real estate valuation. Journal of Property Research, 31(1), pp.45-63.

Todd, P. \& Benbasat, I. (1991). An experimental investigation of the impact of computer based decision aids on decision making strategies. Information Systems Research, 2(2), pp.87-115.

Tversky, A. \& Kahneman, D. (1974). Judgement under uncertainty: heuristic and biases. Science, 185(4157), pp.1124-1131.

Yiu, C.Y., Tang, B.S., Chiang, Y.H. \& Choy, L.H.T. (2006) Alternative Theories of Appraisal Bias. Journal of Real Estate Literature, 14(3), pp.321-344. 


\section{Appendix A - First page of the Valuation Tools, for both Standard (STD) and Decision Support (DSS) Programmes}
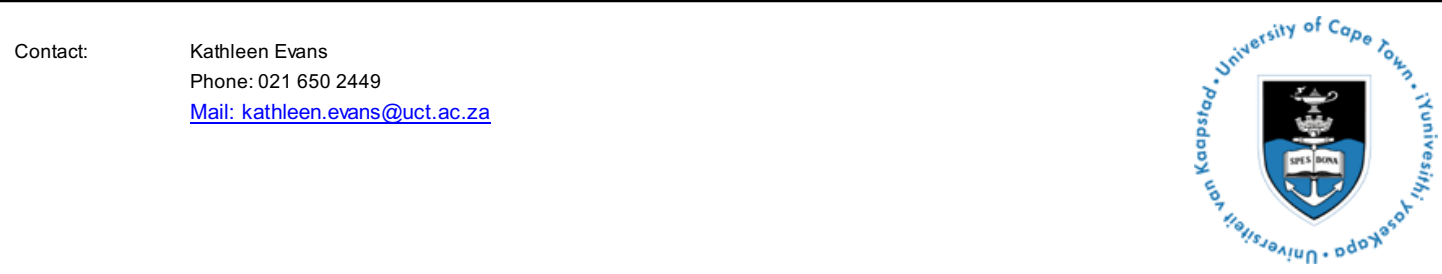

Experiment for the improvement of property valuation software

On this page structure and usage of the software are explained. On the second page you can enter the data from the information package and calculate the market value of the property. The third page collects some statistical data.

Instructions:

1) Activation of macros. Normally you have to click on a warning notice which appears on top of the page under the menu bar saying: "safety warning .... ". If the security settings on your computer do not allow macros, please change them or request a macro free version.

2) Zoom factor setting. Font size and page width are chosen to fit in most screens. You can change the zoom factor under the menu item "view" to see the entire width of the page, if necessary.

3) Click "Start" to begin the valuation!

\section{Start}




\section{Appendix B - Third page of the valuation tools, for both Standard (STD) and Decision Support (DSS) Programmes}

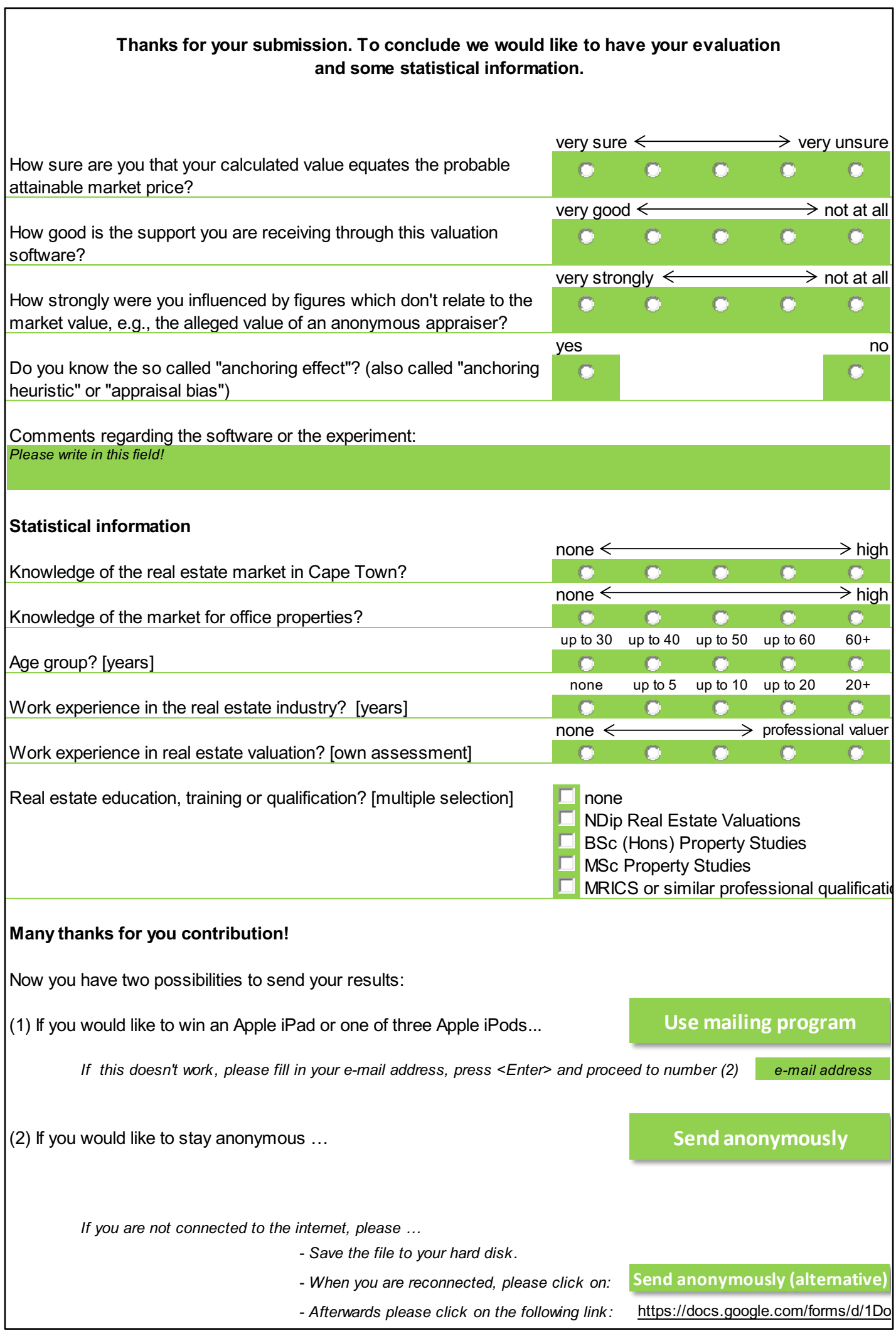




\section{Appendix C - Second page for Standard (STD) Programme Only}

Please enter your values in the dark green fields. The light green fields are already filled for your convenience.

\section{Calculation of market value as of August 1, 2015}

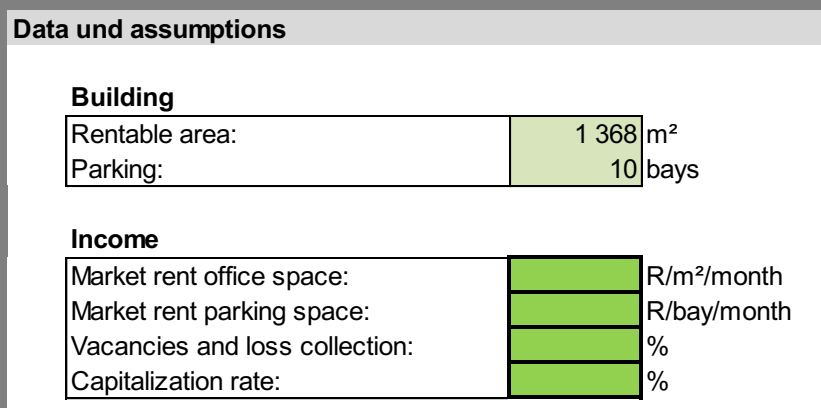

\section{Expenses}

Rates and taxes:

Insurance:

Utilities:

Leasing commissions:

Maintenance allowance:

Property management:

Capitalization rate:

Calculation (Income Approach)

Potential Gross Income Rental income (offices): Other income (parking lots):

- Vacancy and Collection Losses

= Effective Gross Income

$$
\% * 0=
$$

- Operating Expenses

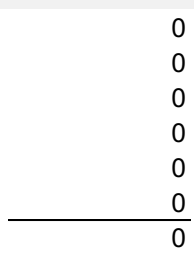

Rates and taxes:

Insurance:

Utilities:

Leasing commissions:

Maintenance allowance:

Property management:

$=$ Net Operating Income

$0.00 \%$

$\div$ Capitalization Rate

$=$ Provisional Market Value

+/- Adjustments

= Market Value

When you have filled in all the data and if you are satisfied with the result of the calculation please click on "End" to finish the valuation.

\section{End}




\section{Appendix D - Second page for Decision Support (DSS) Programme Only}

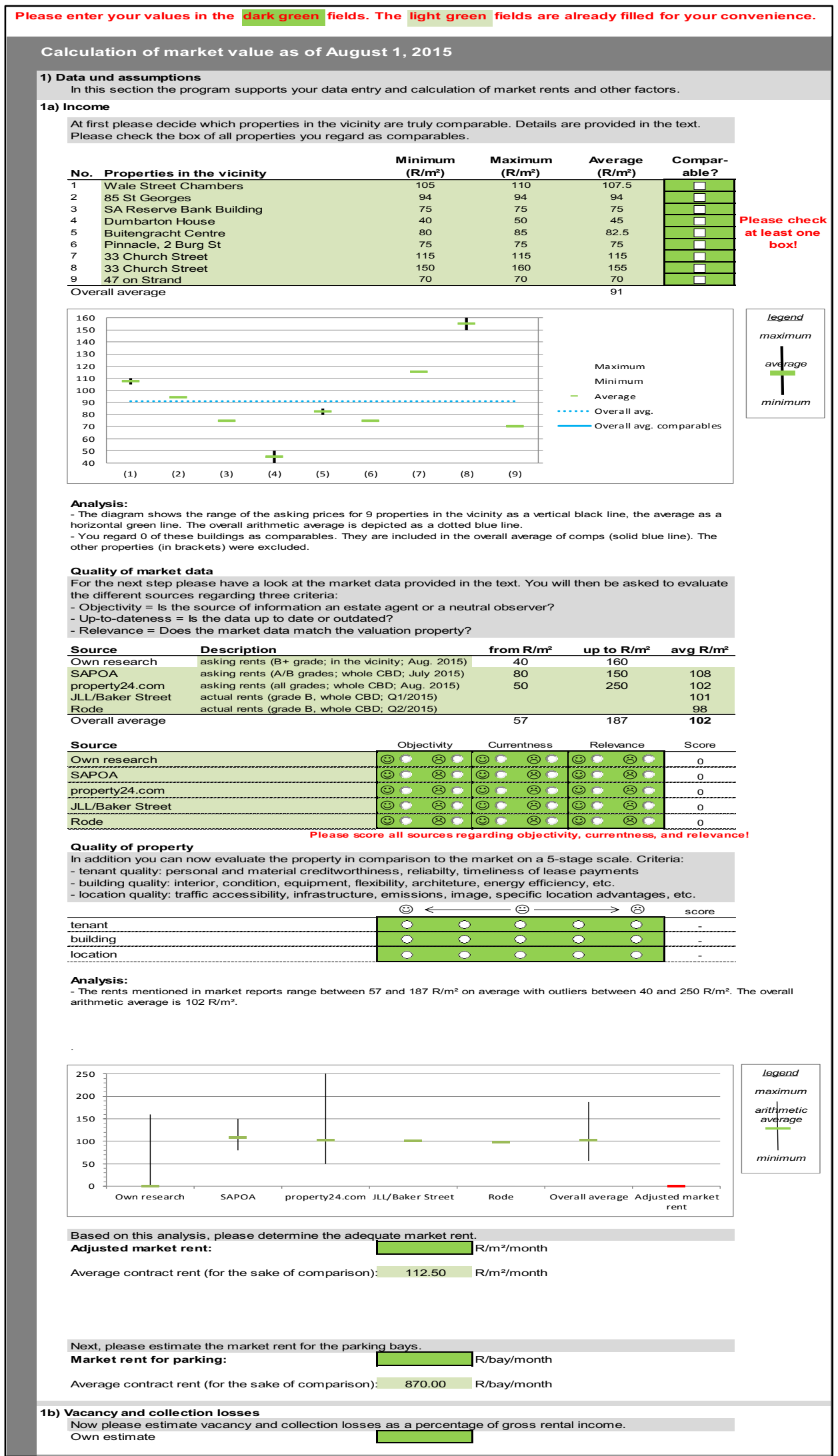


Journal of African Real Estate Research Volume 4(1) 2019

1c) Operating expenses
In the next step the software helps you to calculate the operating expenses. At first please estimate the total expenses with the help of a cost-to-income ratio. After that you can allocate that sum to the individual

expenses.

Cost-to-income ratio (based on estimated market rent for a fully-let property and actual expenses): Rental income per year

Office: $\mathrm{R} O * 1,368 \mathrm{~m}^{2} * 12$ months $=$

Parking: $R O^{*} 10$ bays * 12 months $=$

Actual expenses per year $\quad 498000 \mathrm{R} / \mathrm{year}$ 0 R/year

O R/year

\begin{tabular}{l} 
Comparison \\
\begin{tabular}{l|l}
\hline Actual ratio \\
\hline Market data & low \\
\hline Own estimate & high \\
\hline
\end{tabular} \\
\hline
\end{tabular}

Estimated expenses per year

498000 R/year

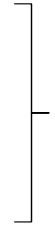

Now please allocate the total expenses to the various expense items by overwriting the percentage figures in the dark green boxes. If you feel that the current portions are ok you can leave them as they are. In any case the sum must equal $100 \%$.

\begin{tabular}{lrr|rr} 
& $\begin{array}{c}\text { Rand } \\
\text { actual }\end{array}$ & $\begin{array}{c}\text { Portion } \\
\text { actual }\end{array}$ & $\begin{array}{r}\text { Rand } \\
\text { estimated }\end{array}$ & $\begin{array}{c}\text { Portion } \\
\text { estimated }\end{array}$ \\
Rates and taxes: & 201000 & $40 \%$ & 201000 & $40 \%$ \\
Insurance: & 12000 & $2 \%$ & 12000 & $2 \%$ \\
Cleaning \& security: & 48000 & $10 \%$ & 48000 & $10 \%$ \\
Leasing commissions: & 70000 & $14 \%$ & 70000 & $14 \%$ \\
Maintenance allowance: & 65000 & $13 \%$ & 65000 & $13 \%$ \\
\hline Property management: & 102000 & $20 \%$ & 102000 & $20 \%$ \\
\hline Total & 498000 & $100 \%$ & 498000 & $100 \%$ \\
\hline
\end{tabular}

1d) Capitalization rate

From the information given in the documents please estimate the cap rate

\begin{tabular}{llccc} 
Source & Description & from & up to & average \\
\hline SAPOA & office buildings, Cape Town CBD & $8.10 \%$ & $10.60 \%$ & $8.60 \%$ \\
Rode-Grade A & office buildings, Cape Town CBD, grade A & $8.30 \%$ & $9.50 \%$ & $8.90 \%$ \\
Rode-Grade B & office buildings, Cape Town CBD, grade B & $9.20 \%$ & $9.80 \%$ & $9.50 \%$ \\
\hline
\end{tabular}

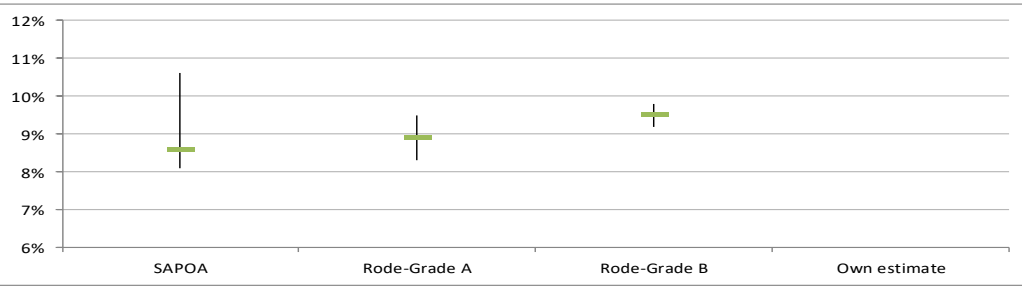

2) Calculation (Income Approach)

Potential Gross Income

Rental income (offices): $\quad \mathrm{R} 0 * 1,368 \mathrm{~m}^{2 *} 12$ months

Other income (parking lots): $\quad \mathrm{R} 0$ * 10 bays * 12 months

- Vacancy and Collection Losse

= Effective Gross Income

- Operating Expenses

Rates and taxes:

Insurance:

Cleaning \& security:

Leasing commissions:

Property management:

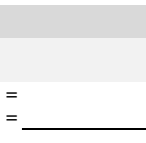

= Net Operating Income

$\div$ Capitalization Rate

$0 \% * 0=$

0

= Provisional Market Value

+/- Adjustments

= Market Value 
Journal of African Real Estate Research Volume 4(1) 2019

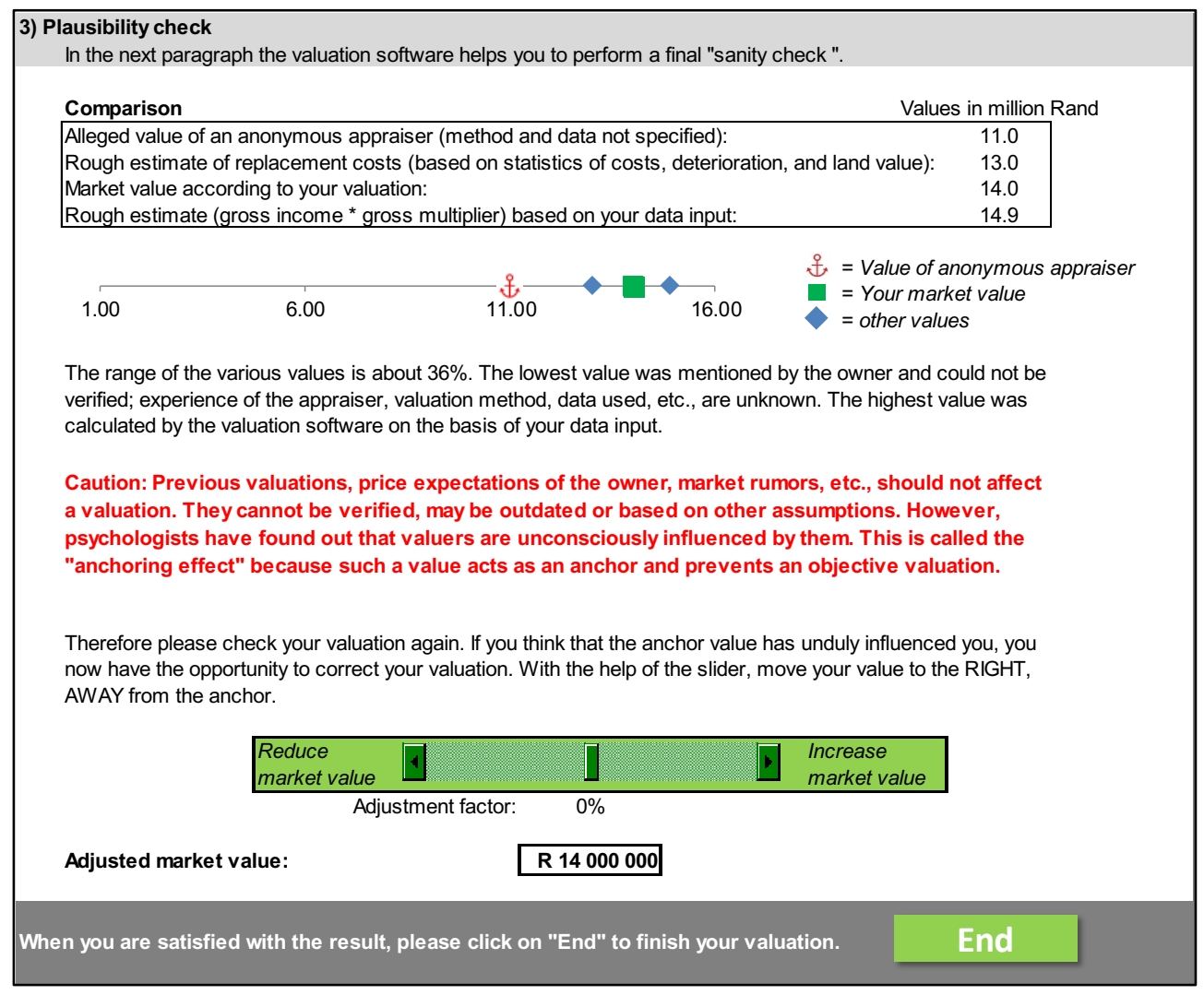

